\title{
EFFECT OF TECHNOLOGICAL PARAMETERS OF LASER AND LASER-PLASMA ALLOYING ON PROPERTIES OF 38KhN3MFA STEEL LAYERS
}

\author{
L.I. MARKASHOVA, V.D. SHELYAGIN, O.S. KUSHNARYOVA and A.V. BERNATSKY \\ E.O. Paton Electric Welding Institute, NASU \\ 11 Bozhenko Str., 03680, Kiev, Ukraine. E-mail: office@paton.kiev.ua
}

\begin{abstract}
The results of investigations of structural-phase conditions in surface layers of structural steel 38KhN3MFA and their changes under different modes of strengthening by laser and laser-plasma alloying are given. Experimental investigations were used as a basis for analytical evaluation of differential input of all structures being formed in strengthening and their parameters (chemical composition, grain and subgrain structures, dislocation density, volume fraction of phase precipitates etc.) in change of strength characteristics of alloyed layers, conditions of crack formation promoted by formation of local internal stress concentrators, i.e. zones of nucleation and propagation of cracks, as well as mechanisms for relaxation of such type of stresses. 12 Ref., 6 Figures.
\end{abstract}

Key words: structural steel, working surface, laser and laser-plasma surface alloying, structure, substructure, phase precipitates, dislocation density, service properties of surfaces

One of the main tasks in manufacture of parts of machines and mechanisms is providing of their service properties, that, as a rule, depend on conditions of their operation and corresponding properties of materials, from which these parts are manufactured [1]. As for the structures with specific properties of their surfaces, then their working capacity and increase of life of such types of structures can be provided, first of all, by corresponding technologies for surface layer strengthening. Today, laser and laser-plasma methods of treatment are referred to them [2].

It should be noted that conditions of operation of indicated technologies provide for appearance of problems related to significant extent with accumulation of local internal stresses in treated surfaces, that is the main reason of reduction of crack resistance and, respectively, reduction of properties of the whole structure.

It should be noted that virtually all properties, including material crack resistance, are determined by their structural-phase condition. Investigation of nature of structures and their changes in surface layers of metal under conditions of different technological treatments in combination with further evaluation of effect of forming structures on their service properties is a relevant task. Such an experimental-analytical approach gives a possibility for providing necessary service properties of hardened surfaces due to optimization of surface structures [3-5].
Experimental information on structure-phase condition of alloyed layers of structural steel $38 \mathrm{KhN} 3 \mathrm{MFA}$ (surface of circular specimens $187 \times 125 \times 30 \mathrm{~mm})$ and its changes was received for conditions of laser and laser-plasma alloying [6] using mechanical mixture of powders of 0 $40 \mu \mathrm{m}$ fraction of the following composition, wt.\%: 46( $\left.\mathrm{WC}-\mathrm{W}_{2} \mathrm{C}\right)+46 \mathrm{Cr}+4 \mathrm{Al}+4 \mathrm{Si}$ (laser alloying) and $48\left(\mathrm{WC}-\mathrm{W}_{2} \mathrm{C}\right)+48 \mathrm{Cr}+4 \mathrm{Al}$ (laser-plasma alloying). Following modes of treatment were used at that: power $P=3.5-4.4 \mathrm{~kW}$; alloying speed $v=400-750 \mathrm{~mm} / \mathrm{min}$ at radiation defocusing $\Delta F=+(30-45) \mathrm{mm}$ at laser alloying method. Laser-plasma alloying was performed at constant $P=3 \mathrm{~kW}$, varying $v=500-$ $750 \mathrm{~mm} / \mathrm{min}$ with overlaying of different number of paths.

The following was determined using complex examinations at all structural levels from macro (grain) to micro (dislocation) one [7] using light (Versamet-2), analytical scanning (Philips SEM515) as well as transmission microdiffraction electron microscopy (JEOL JEM-200CX).

Surface alloyed layer at all investigated methods of treatment has obvious crystalline structure. However, modes of laser-plasma treatment are characterized by reduction of sizes and prevailing of more globular (cell) nature of structures forming in surface layers (Figure 1). The most problematic defective zones for all investigated surfaces (at laser as well as laser-plasma alloying) are areas of microcracks, in which rapid increase of chromium concentration (up to $25 \%$ ) is observed (Figure 2). However, if cracks are observed not only in alloyed layer, but also in fusion zone and base metal under conditions of 

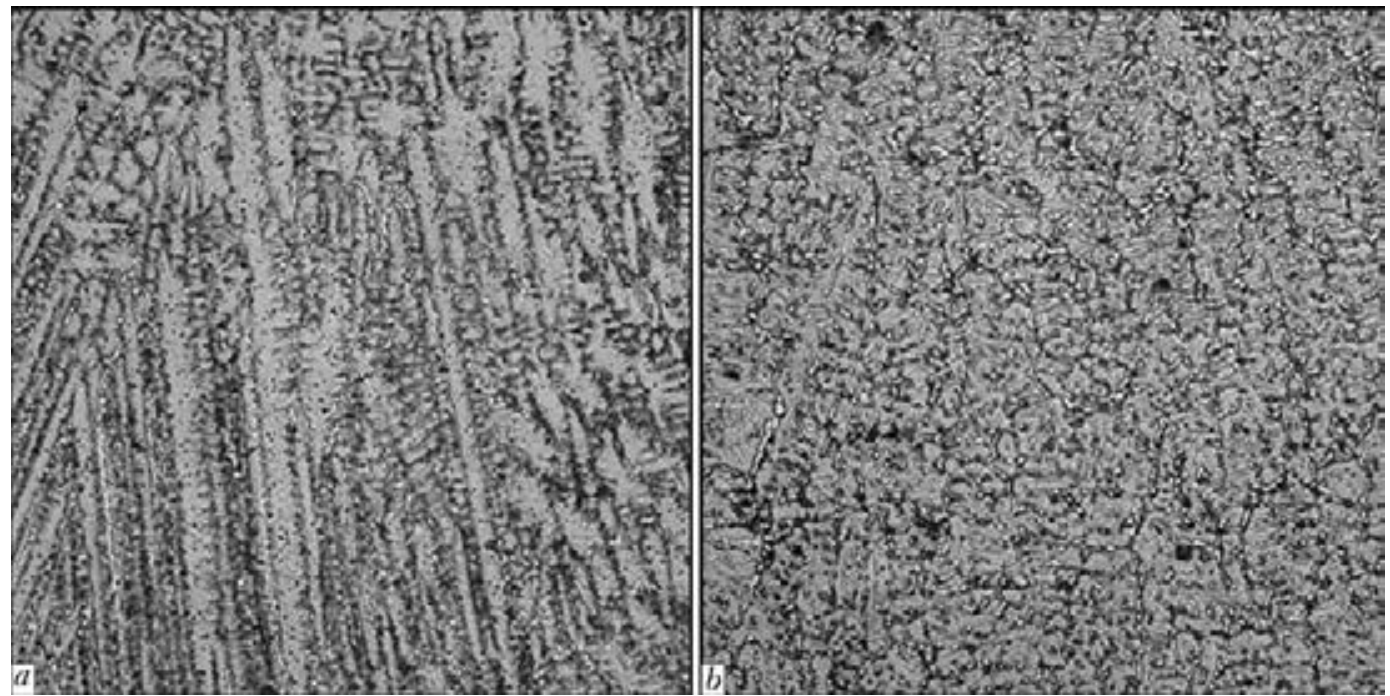

Figure 1. Microstrucutre $(\times 500)$ of surface of structural steel 38KhN3MFA under conditions of laser $(a)$ and laser-plasma (b) alloying

laser treatment, then areas of crack propagation are significantly reduced under laser-plasma alloying. No cracks are found in fusion zone and, moreover, in base metal [6]. More detailed parallel investigations were carried out using specimens produced at optimum technological modes (absence of cracks or their minimum quantity) and at deviations from optimum mode (conditions of formation of significant quantity of cracks) for detection of reasons of crack formation appearing under specific technological modes of surface treatment.

It was determined that laser alloying at $P=$ $=4.4 \mathrm{~kW}, v=400 \mathrm{~mm} / \mathrm{min}$ (deviation from optimum mode) provides for formation in treated surface layers of the structure differing by increased indices of microhardness ( $H V$-4830$5720 \mathrm{MPa}$ ). Their values exceed corresponding indices of base metal ( $H V-3760-3820 \mathrm{MPa})$, i.e. gradient of microhardness $\Delta H V$ from surface to base metal makes around 1070-850 $\mathrm{MPa}$. Besides, insignificant microporosity (volume fraction up to $V_{\mathrm{fr}} \sim 1 \%$ ) is typical for treated surfaces. As for type of forming structures and their size, then investigations showed that indicated modes of treatment provides for formation in alloyed surface layers of structures of mainly acicular type, including martensite, as well as structures of upper and lower bainite saturated with elongated $(h \times l=(0.06-0.10) \times(1.0-1.6 \mu \mathrm{m}))$ carbides of grain boundary type (Figure $3, a$ ). Coarse grain acicular structures $(h \times l$ up to $\sim 15 \times$ $\times 150 \mu \mathrm{m})$ with coefficient of grain shape up to $\kappa \sim 10$ should be noted at that. It indicates extension of structures forming in surface layers.

Examinations of concentration changes as well as presence and distribution of particles of phase formations of different compositions, being introduced in treatment together with powder mixture, showed comparatively uniform distribution of inclusions of size up to $\sim 25 \mu \mathrm{m}$ in internal volumes of grains of alloyed layers under indicated treatment. They mainly consist of tungsten carbides $\left(\mathrm{WC}+\mathrm{W}_{2} \mathrm{C}\right)$ of $V_{\mathrm{fr}} \sim 1 \%$. Formation of local zones of increase chromium concentration (up to $\sim 20-25 \%$ ), which are distributed, as a rule, along intergrain boundaries, is also observed. Areas of such type are clearly registered

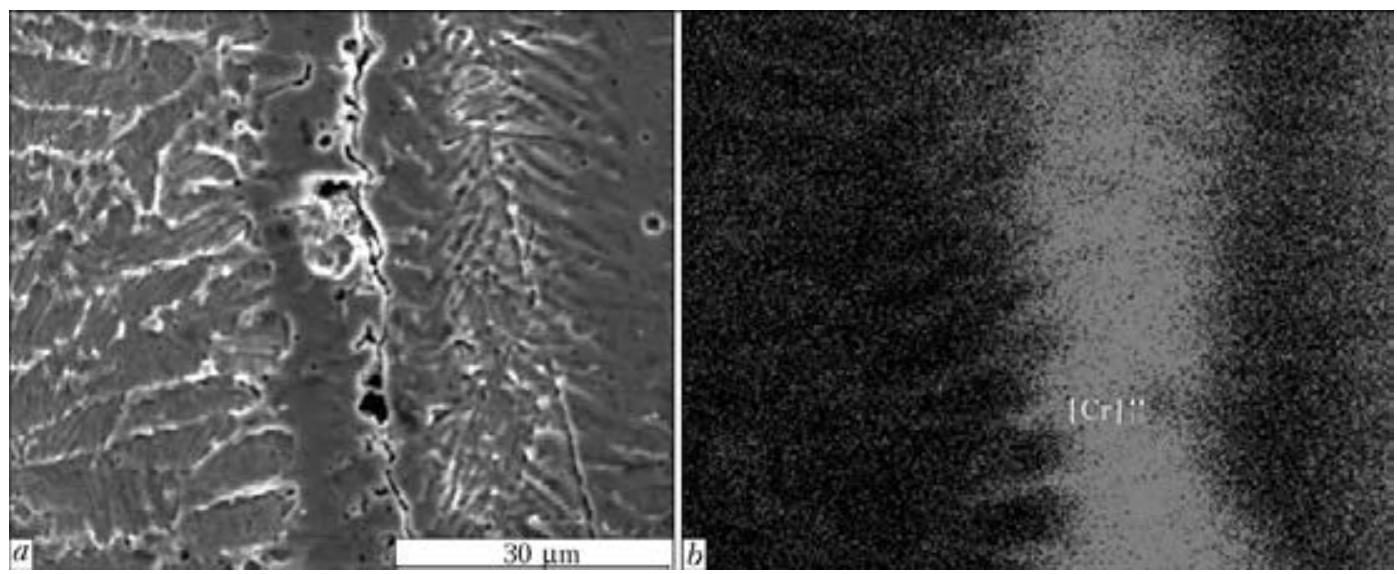

Figure 2. Image of microcracks in area of surface alloyed layer $(a)$, and distributon of chromium along this crack (b) 

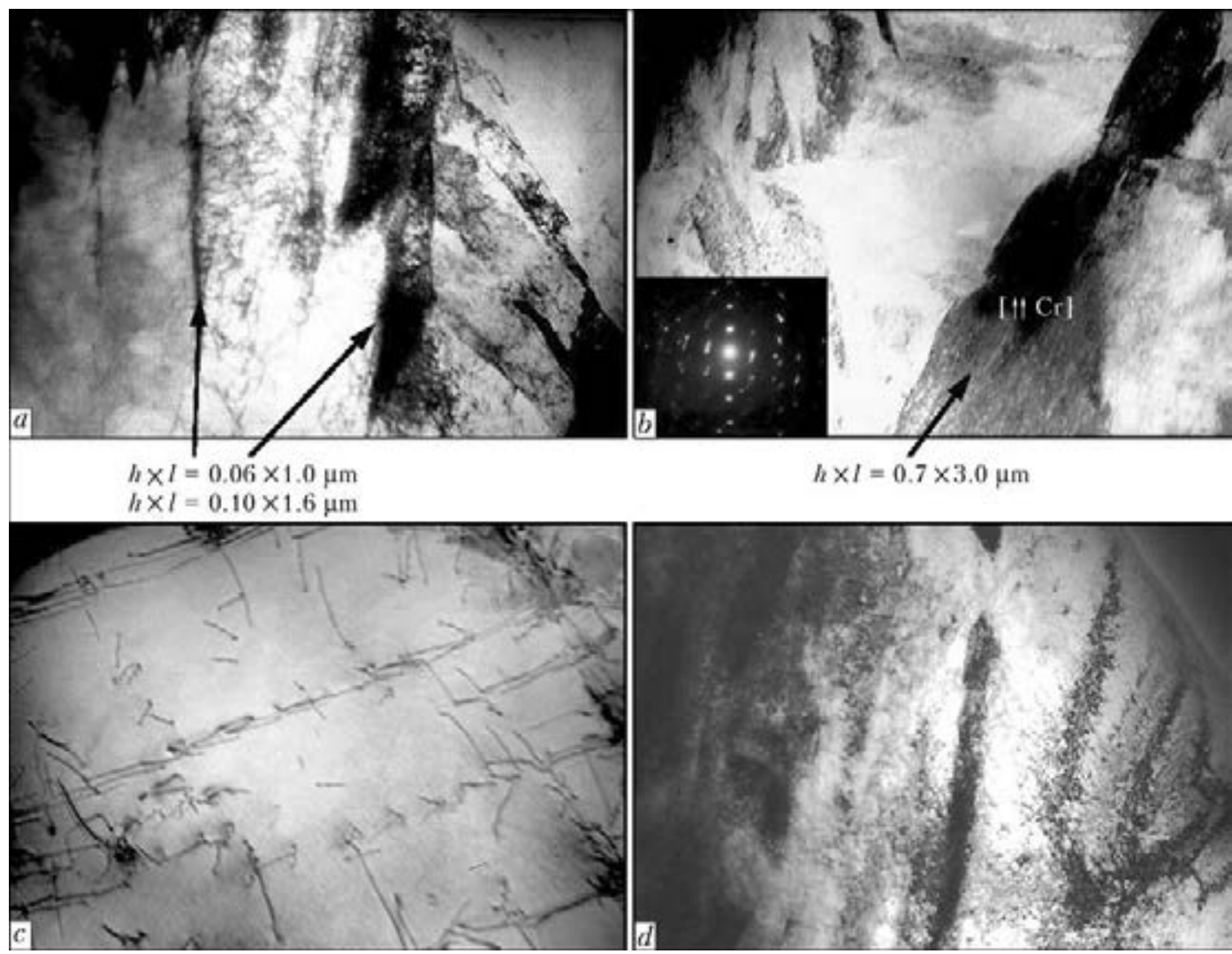

Figure 3. Fine structure of surface layer produced by laser alloying at $P=4.4 \mathrm{~kW}, v=400 \mathrm{~mm} / \mathrm{min}: a-$ gradient of distribution of dislocations along phase precipitates in internal volumes of crystalline particles $(\times 37,000) ; b-$ internal strturture of phase precipitates $(\times 30,000)$; and at $P=3.5 \mathrm{~kW}, v=500 \mathrm{~mm} / \mathrm{min}: c-$ uniform distribution of dislocation density in austenite structure $(\times 20,000) ; d-$ martensite structure $(\times 30,000)$

on maps of chemical elements distribution during corresponding examinations.

In the case of investigated modes of laser alloying, metal layers within thin (dislocation structure) is characterized by uniform distribution of dislocation density differing by rapid increase (mainly along intergrain boundaries) of dislocation density up to $\rho \sim 9 \cdot 10^{11}-1 \cdot 10^{12} \mathrm{~cm}^{-2}$ values that is significantly higher than the values of intergrain dislocation density $\left(\rho \sim 8 \cdot 10^{8}-2 \cdot 10^{10} \mathrm{~cm}^{-2}\right)$. Elongated dense dislocation accumulations of such type are, as a rule, interlocked with sufficiently high near-boundary concentration distributions of chromium, and, respectively, formation in this zone (along intergrain boundaries) of Cr-containing carbide phases $\left(\mathrm{Cr}_{23} \mathrm{C}_{6}\right.$ type) (see Figure $\left.2, b\right)$.

Radical changes of structure-phase conditions of treated surfaces are observed in the case of optimum mode of laser alloying $(P=3.5 \mathrm{~kW}$, $v=500 \mathrm{~mm} / \mathrm{min})$ in comparison to mode with deviation from optimum one. The surfaces are characterized by formation of more fine-grain martensite-austenite structure (Figure 3,c,d) (grain size $h \times l$ is reduced to $40 \times 125 \mu \mathrm{m}$ ) at significant decrease of grain shape coefficient $(\kappa \sim 3)$. It indicates not only fine gran structure, but equiaxial surface structure under conditions of optimum modes of treatment.
Distribution of chemical elements being entered at optimum treatment appears to be relatively uniform, i.e. for instance, if chromium and tungsten content in grain volumes is registered at the level of $\sim 6$ and $7 \%$, respectively, then increase of such types of concentrations is insignificant (up to $\sim 8$ and $9 \%$ ) in near-boundary areas. The latter shows absence of significant gradient in distribution of chemical elements entered by treatment in metal surface areas. Besides, it should be noted that surface layers contain minimum quantity of pores as well as rapid $(\sim 1 \%)$ reduction of quantity of cracks and insignificant change of microhardness in surface-base metal zone.

Peculiarities of formation of dislocation structure in surface layers are indicative for optimum modes of laser surface treatment: more uniform distribution of dislocations at general reduction of their density $\left(\rho \sim(2-4) \cdot 10^{9} \mathrm{~cm}^{-2}\right)$ (Figure 3, $c)$ are typical for these alloying cases. Relative uniformity should be noted in connection to size and distribution of particles of phase precipitates which are more disperse (their sizes of about 0.04$1.2 \mu \mathrm{m})$ and have comparatively uniform distribution mainly in internal grain volumes in surface layers under conditions of optimum laser treatment. Moreover, entered coarse particles of tungsten carbide $\left(\mathrm{WC}+\mathrm{W}_{2} \mathrm{C}\right)$ are virtually absent. 

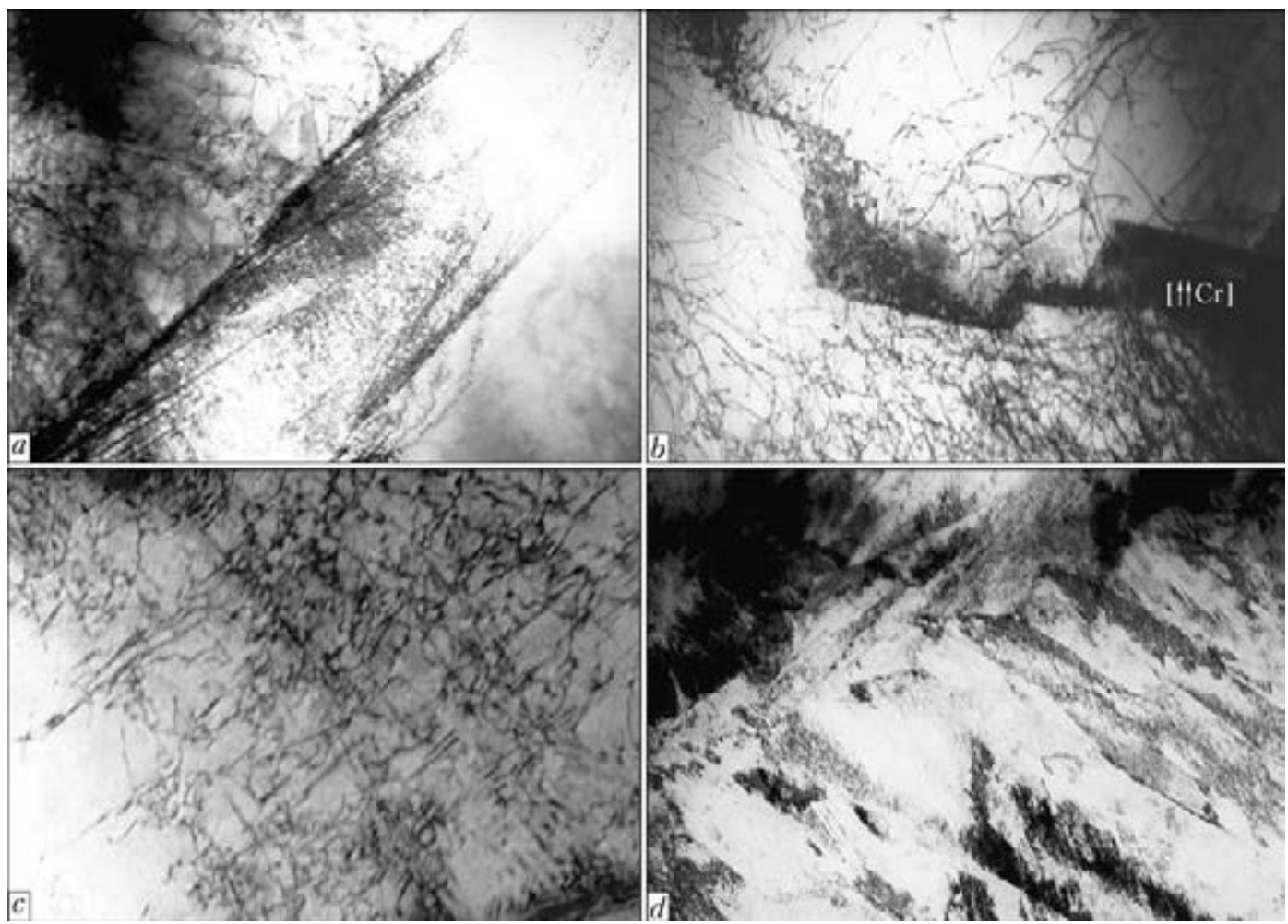

Figure 4. Fine structure of laser-plasma alloyed layer at $P=3 \mathrm{~kW}, v=500 \mathrm{~mm} / \mathrm{min}$ with overlaying of four paths: rapid gradient in distribution of dislocation density in crystalline particles volume $(a-\times 30,000)$ as well as along the boundaries $(b-\times 20,000)$; and at $P=3 \mathrm{~kW}, v=500 \mathrm{~mm} / \mathrm{min}$ with overlaying of one path: uniform distribution of dislocation density and phase precipitates $(c, d-\times 30,000)$ in metal of alloyed layer

The following is typical under conditions of laser-plasma alloying in the case of deviation from optimum mode $(P=3 \mathrm{~kW}, v=$ $=500 \mathrm{~mm} / \mathrm{min}$ with overlaying of four paths) for treated alloyed layers of metal: formation of acicular type structure, but with grain size coarsening ( $h \times l$ up to $20 \times 150 \mu \mathrm{m})$ and coefficient of their shape $(\kappa \sim 8)$; increase of quantity (to $\sim 10 \%$ ) of coarse inclusions ( $\left.\mathrm{WC}+\mathrm{WC}_{2}\right)$ of up to $50-230 \mu \mathrm{m}$ size; rise of surface microhardness $H V$ and porosity (to $\sim 20 \%$ ) as well as significant enough increase of quantity of cracks (to $30 \%$ ) in surface layers.

Besides, quite considerable changes of chromium concentration in specific structural zones are also determined, i.e. increase (to $17 \%$ and more) of chromium is observed mainly along the zones of intergrain boundaries and fusion line. Clear localization of processes of crack formation along the fusion line is also typical for indicated modes. They differ by the largest gradient in chromium concentration $(\Delta \mathrm{Cr} 15 \%)$ and formation of elongated dislocation clusters with high density (to $\rho \sim 8 \cdot 10^{11} \mathrm{~cm}^{-2}$ ) (Figure $3, a, b$ ).

Optimum mode of laser-plasma alloying $(P=$ $=3 \mathrm{~kW}, v=500 \mathrm{~mm} / \mathrm{min}$ with one path) provides for following typical moments for metal of alloyed layers: some increase of surface layer hardness, but without gradient in comparison with base metal; significant dispersion of marten- site structure, carbide phases and inclusions (WC $+\mathrm{W}_{2} \mathrm{C}$ ); uniform distribution (in volumes as well as along the grain boundaries) of such chemical elements as chromium and tungsten as well as complete absence of porosity and cracks. General reduction of dislocation density (to $\rho \sim 8 \cdot 10^{8}$ $1 \cdot 10^{9} \mathrm{~cm}^{-2}$ ) at uniform their distribution along whole volume of surface layer (Figure $4, c, d$ ) is also characteristic for optimum mode of laserplasma treatment.

Carried complex of experimental investigations allowed performing analytical estimations of differential input of different structural-phase constituents and their parameters, forming in investigated layers under different modes of alloying, as well as concentration of alloying elements in change of the most significant service characteristics of treated surfaces, namely, strength and crack resistance. Analytical estimations of integral value of yield strength $\Sigma \sigma_{\mathrm{y}}$ were carried out using known dependence [8-11]:

$$
\Sigma \sigma_{\mathrm{y}}=\Delta \sigma_{0}+\Delta \sigma_{\mathrm{s} . \mathrm{s}}+\Delta \sigma_{\mathrm{g}}+\Delta \sigma_{\mathrm{s}}+\Delta \sigma_{\mathrm{d}}+\Delta \sigma_{\mathrm{d} . \mathrm{s}}
$$

including $\Delta \sigma_{0}$ - the resistance of metal lattice to movement of free dislocations (lattice friction stress or Peirels-Nabarro stress); $\Delta \sigma_{\text {s.s }}-$ the strengthening of solid solution by alloying elements and additives (solid-solution strengthening); $\Delta \sigma_{\mathrm{g}}, \Delta \sigma_{\mathrm{S}}-$ the strengthening due to change 


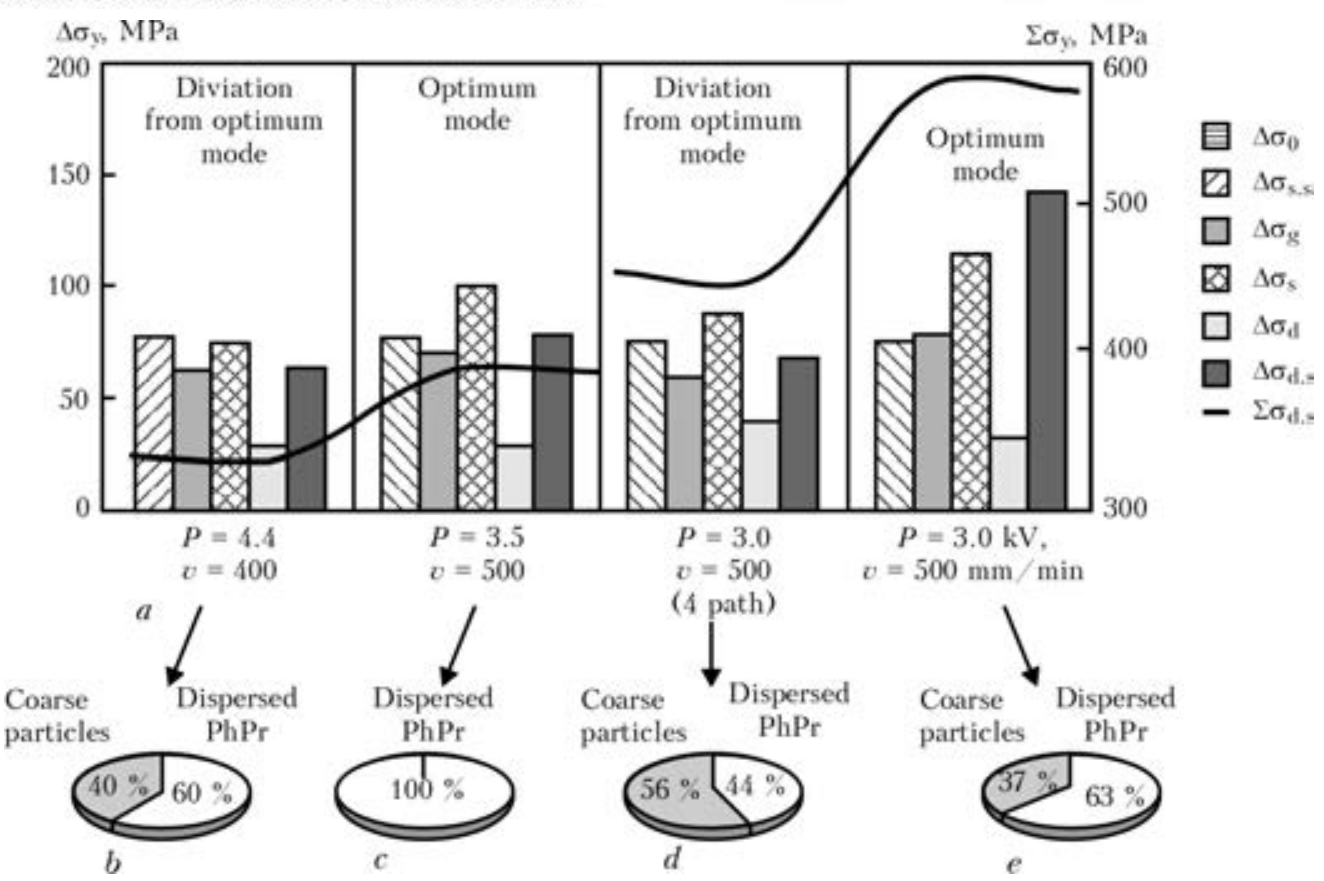

Figure 5. Histogram $(a)$ of differential input of structural constituents in total calculated value of yield strength (integral $\Sigma \sigma_{\mathrm{y}}$ ) of surface alloyed by laser and laser-plasma method; $b-e-$ pie chart of percent relationship of input of disperse and coarse phase precipitates in $\Sigma \sigma_{\mathrm{y}}$

of grain and subgrain value (by Hall-Petch dependence for grain-boundary and subgrain strengthening); $\Delta \sigma_{d}-$ the dislocation strengthening caused by interaction between dislocations; and $\Delta \sigma_{\text {d.s }}-$ the strengthening due to particles of phase transformations by Orowan (dispersion strengthening).

The results of evaluation showed that the highest total values of yield strength $\Sigma \sigma_{y}$ in treated surfaces are provided at optimum modes of laser alloying $\left(\Sigma \sigma_{\mathrm{y}}=406 \mathrm{MPa}\right)$ as well as laser-plasma alloying $\left(\Sigma \sigma_{\mathrm{y}}=591 \mathrm{MPa}\right)$ (Figure 5, a). Moreover, the largest input in increase of yield strength in laser alloying (optimum mode) is provided due to substructure refining $\left(\Delta \sigma_{\mathrm{s}}=\right.$ $=115 \mathrm{MPa})$ that under these conditions makes around $28 \%$ of total $\Sigma \sigma_{\mathrm{y}}$ value. In laser-plasma allying (optimum mode) the maximum input in increase of $\Sigma \sigma_{\mathrm{y}}$ is provided by substructure refining $\left(\Delta \sigma_{\mathrm{s}}=176 \mathrm{MPa}\right.$, i.e. $30 \%$ of $\left.\Sigma \sigma_{\mathrm{y}}\right)$ and effect of phase precipitates $\left(\Delta \sigma_{\text {d.s }}=196 \mathrm{MPa}\right.$, i.e. $33 \%$ of $\Sigma \sigma_{\mathrm{y}}$ ) (Figure $5, a, e$ ). It should be noted that rise of level of dispersion strengthening $\Delta \sigma_{\mathrm{d} . \mathrm{s}}$ in the latter case takes place to significant extent due to input of dispersed phases $(\sim 63 \%)$ and less significant contribution from coarse inclusions based on tungsten carbide $(\sim 37 \%$ ) (Figure $5, e)$.

The results of investigations at all structural levels allowed carrying also evaluation of such quite considerable indices of mechanical properties as indices of crack resistance of alloyed layers of surfaces being treated under different investigated modes. Analysis of crack resistance indices was carried out considering distribution of dislocation density based on evaluation of level of local internal stresses according to dependence [12] $\tau_{1 . \text { in }}=G b h \rho /[\pi(1-v]$, where $G$ is the shear modulus; $h$ is the foil thickness; $v$ is the Poisson's ratio. Conditions when $\tau_{1 . \text { in }}$ value in specific area approaches to value of theoretical strength $\tau_{\text {theor }}$ of material, this area (with specific structuralphase condition) is a zone of nucleation and propagation of cracks.

It shown as a result that sharp changes of dislocation density in specific zones of metal, where it varied from $\rho=9 \cdot 10^{11}-1 \cdot 10^{12}$ to $8 \cdot 10^{8}$ $2 \cdot 10^{10} \mathrm{~cm}^{-2}$, are typical for surface layers forming under conditions of laser alloying at $P=4.4 \mathrm{~kW}$, $v=400 \mathrm{~mm} / \mathrm{min}$ (deviation from optimum mode). Present of such type of zones is a basis for formation in these areas of alloyed layers with sharp gradients in value of local internal stresses being the concentrators of internal stresses and, respectively, factors, promoting crack formation and rapid deterioration of surface quality. In this case $\Delta \tau_{1 . i n}$ values vary from $18500\left(G / 4.5 \cdot 10^{3}\right.$ corresponds to $\left.2.2 \tau_{\text {theor }}\right)$ to $14.9 \mathrm{MPa}\left(G / 5.7 \cdot 10^{3}\right.$ corresponds to $0.0018 \tau_{\text {theor }}$ ) (Figure 6 ).

The main reason providing non-uniformity in distribution of dislocation density and so local internal stresses, as can be seen from comparison of investigation results, is significant local increase (preferably along the intergrain boundaries) of concentration of such chemical elements as chromium, as well as formation in this zone of elongated Cr-containing phases $\left(\mathrm{Cr}_{23} \mathrm{C}_{6}\right)$. 
Reduction of dislocation density to $\sim 4 \cdot 10^{9} \mathrm{~cm}^{-2}$ and their uniform distribution are observed in treated surfaces in the case of laser alloying at decrease $P=3.5 \mathrm{~kW}$ and increase $v=$ $=500 \mathrm{~mm} / \mathrm{min}$ (optimum mode). This, respectively, results not only to reduction, but optimum (uniform) distribution of local internal stresses to $\tau_{\text {l.in }} \sim 55.4 \mathrm{MPa}\left(G / 9 \cdot 10^{2}-0.007 \tau_{\text {theor }}\right)$ in alloyed layer, that, as a result, develops conditions for formation of zones of nucleation and propagation of cracks. It is typical that in this case no significant variations are observed in surface layers at distribution of concentrations of such chemical elements as chromium, promoting formation of local dislocation clusters.

Rapid gradient in distribution of dislocation density in crystalline particle volumes is observed in the sample after laser-plasma alloying $(P=$ $=3 \mathrm{~kW}, v=500 \mathrm{~mm} / \mathrm{min}$ with overlaying of four path, deviation from optimum mode). There increase of chromium concentration (to $17 \%$ ) is clearly evident, that is the main reason for formation of elongated internal stresses, i.e. spots of crack nucleation, where $\tau_{\text {l.in }}$ makes from $\sim 370 \mathrm{MPa}\left(G / 2.3 \cdot 10^{2}-0.04 \tau_{\text {theor }}\right)$ to $14000 \mathrm{MPa}\left(G / 6-1.8 \tau_{\text {theor }}\right)$. In the case of laser-plasma alloying at $P=3 \mathrm{~kW}, \quad v=$ $=500 \mathrm{~mm} / \mathrm{min}$ (optimum mode), presence of discrete on size and uniformly distributed on volume grains of phase precipitates at accompanying low dislocation density (without rapid gradients in its distribution) indicates the absence of structural conditions for formation of internal stress concentrators.

At that, $\tau_{1 . \text { in }}$ values are reduced and make 2148-370 $\left(G / 5.7 \cdot 10^{2}-G / 2.3 \cdot 10^{2}-(0.018-\right.$ $0.04) \tau_{\text {theor }}$ (Figure 6 ). The latter helps to characterize structural condition of surface as optimum and verifies practical absence of cracks.

Thus, experimental-analytical investigations determined effect of structural-phase condition of metal of alloyed layers, forming at different modes of strengthening, on change of strength characteristics and crack resistance of treated surfaces. It is shown that modes of laser-plasma alloying promote for increase of strength (on average by $20 \%$ ) in comparison with laser alloying by irradiation with Gaussian distribution of beam intensity, and phase precipitates (27\%) and substructure (25\%) make the largest input in strengthening at optimum mode. Laser-plasma alloying $(P=3 \mathrm{~kW}, v=500 \mathrm{~mm} / \mathrm{min}$ with overlaying of one path) provides for the maximum crack resistance of alloyed layers. It is promoted by absence of zones of nucleation and propagation of cracks, caused by uniform distribution of dis-

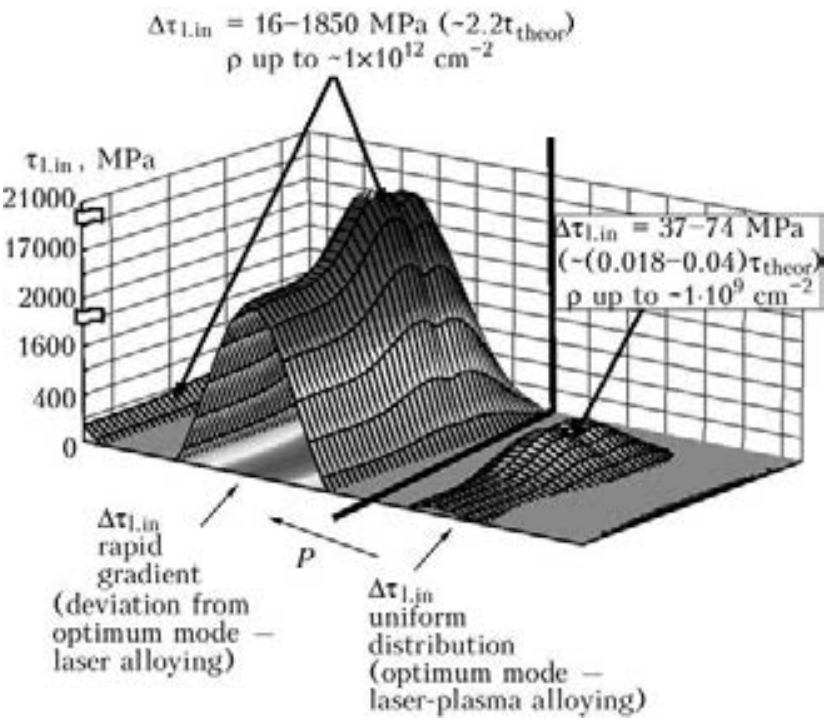

Figure 6. Diagram of distribution of local internal stresses $\tau_{l} /$ in in alloyed layer depending on nature of forming structures and dislocation density

location density without its rapid gradients. Crack formation in laser and laser-plasma strengthening of alloyed layers of structural steel, as a rule, is related with formation of dense and elongated dislocation clusters (mainly along the intergrain boundaries), that provides for nonuniformity in distribution of such chemical elements as chromium.

1. Kurdyumov, V.Ya., Ryazanov, V.P. (1973) Repair of building machines by methods of welding and surfacing. Moscow: Strojizdat

2. Teregulov, N.G., Sokolov, B.K., Varbanov, G. et al. (1993) Laser technologies at machine-building plant. Ufa: AN RB.

3. Markashova, L.I., Ishchenko, A.Ya., Kushnaryova, O.S. et al. (2012)' Effect of structural-phase transformations in aluminium-lithium alloy 1460 joints on physical-mechanical properties. The Paton Welding J., 5, 17-25.

4. Markashova, L.I., Poznyakov, V.D., Gaivoronskii A.A. et al. (2012) Estimation of the strength and crack resistance of the metal of railway wheels after long-term operation. Materials Sci., 47(6), 799-806.

5. Markashova, L.I. Kushnaryova, O.S. (2012) Welded joints of complexly-alloyed aluminium-lithium alloys. Structure and service properties. In: Building. Materials science. Machine-building: Transact., 64, 7580. Dnepropetrovsk: PGASA.

6. Shelyagin, V.D., Markashova, L.I., Khaskin, V.Yu. et al. (2014) Laser and laser-microplasma alloying of surface of $38 \mathrm{KhN} 3 \mathrm{MFA}$ steel specimens. The Paton Welding J., 2, 24-30.

7. Honeycomb, R. (1972) Plastic deformation of metals. Moscow: Mir.

8. Gordienko, L.K. (1973) Ultrafine grain in metals. Moscow: Metallurgiya.

9. Petch, N.J. (1953) The cleavage strength of polycrystalline. J. Iron and Steel Inst., 173(1), 25-28.

10. Orowan, W. (1954) Dislocation in metals. New York: AIME.

11. Kelly, A., Nickolson, R. (1966) Precipitation hardening. Moscow: Metallurgiya.

12. Markashova, L., Kushnareva, O. (2014) Effect of structure on the mechanical properties of the metal of welded joints of aluminium alloys of the $\mathrm{Al}-\mathrm{Cu}-\mathrm{Li}$ system. Materials Sci., 49(5), 681-687. 